Int. J. Electrochem. Sci., 11 (2016) $10592-10606$

\title{
Experimental and Theoretical Studies for Corrosion Inhibition of Copper by 2,5-bis (ethyldisulfanyl)-1,3,4-thiadiazole in Rolling Oil
}

\author{
Sang Xiong, Jianlin Sun ${ }^{*}$, Xudong Yan \\ School of Materials Science and Engineering, University of Science and Technology Beijing, Beijing \\ 100083, China \\ *E-mail: sj1@ustb.edu.cn
}

doi: $10.20964 / 2016.12 .48$

Received: 20 January 2016 / Accepted: 3 March 2016 / Published: 10 November 2016

\begin{abstract}
The effect of 2,5-bis (ethyldisulfanyl)-1,3,4-thiadiazole (DTA) on the corrosion of copper in rolling oil containing aggressive additives was investigated by polarization, electrochemical impedance spectroscopy and weight loss measurement. The inhibition efficiency increases with the increase in concentration of inhibitors and temperature, below 373K. DTA acted as a kind of mixed-type inhibitor, the adsorption of inhibitors on copper surface obeys Langmuir isotherm and chemisorption mechanism. Kinetic model indicating the adsorbed DTA molecules on copper surface block the most active sites. Thermodynamics and quantum chemical calculations demonstrate that the adsorption configuration is found to be stable after corrosion inhibitor by itself decomposes, the sulfur-sulfur bonds are break and electrons are transferred from sulfur to carbon.
\end{abstract}

Keywords: Copper, Corrosion, Electrochemical impedance, Raman spectroscopy, Modelling

\section{$\underline{\text { FULL TEXT }}$}

(C) 2016 The Authors. Published by ESG (www.electrochemsci.org). This article is an open access article distributed under the terms and conditions of the Creative Commons Attribution license (http://creativecommons.org/licenses/by/4.0/). 